\title{
Article \\ Evaluating Groundwater Flow Effects for Enhancement of Ground-Source Heat Pipes in the Case of the Toyohira River Alluvial Fan, Japan
}

\author{
Yoshikata Sakata ${ }^{1, *(D)}$, Johnson Chishimba ${ }^{2}$, Masataka Mochizuki ${ }^{3}$ and Katsunori Nagano ${ }^{1}$ \\ 1 Division of Environmental Engineering, Hokkaido University, Sapporo 060-8628, Japan; \\ nagano@eng.hokudai.ac.jp \\ 2 Graduate School of Engineering, Hokkaido University, Sapporo 060-8628, Japan; \\ johnson.chishimba.d8@elms.hokudai.ac.jp \\ 3 e-Gle Co., Ltd., Kawasaki 212-0032, Japan; mochizuki-m@e-gle.jp \\ * Correspondence: y-sakata@eng.hokudai.ac.jp
}

Citation: Sakata, Y.; Chishimba, J.; Mochizuki, M.; Nagano, K.

Evaluating Groundwater Flow Effects for Enhancement of Ground-Source Heat Pipes in the Case of the Toyohira River Alluvial Fan, Japan. Hydrology 2021, 8, 135. https://doi.org/

10.3390/hydrology 8030135

Academic Editor: Tammo Steenhuis

Received: 27 July 2021

Accepted: 31 August 2021

Published: 8 September 2021

Publisher's Note: MDPI stays neutral with regard to jurisdictional claims in published maps and institutional affiliations.

Copyright: (c) 2021 by the authors. Licensee MDPI, Basel, Switzerland. This article is an open access article distributed under the terms and conditions of the Creative Commons Attribution (CC BY) license (https:// creativecommons.org/licenses/by/ $4.0 /)$.

\begin{abstract}
The purpose of this study was to evaluate the potential enhancement of ground-source heat pipes by groundwater advection at two sites within an alluvial fan of Toyohira River, Sapporo. Two sites were selected: one in the fan toe, for negligible groundwater flow (Site 1), and the other in the apex for fast flows, the latter characterized by a specific discharge of $1.0 \mathrm{~m} / \mathrm{d}$ from the losing river (Site 2). The evaporator section(s) of a single (double) heat pipe(s) was installed in a borehole at each site; the condenser section(s) on the ground was placed inside cooled brine at a set temperature, resulting in heat extraction under steady conditions. The single heat pipe experiments showed that the heat extraction rates ranged between 0.23 and $0.79 \mathrm{~kW}$ and were not clearly different at the two sites, considering some uncertainty. For double heat pipes, the heat extraction rates were unchanged at Site 1, but were about $146 \%$ higher at Site 2 compared to the single tests, due to groundwater advection. This study revealed that the number of ground-source heat pipes required could be reduced from three to two in areas near Site 2.
\end{abstract}

Keywords: heat pipe; groundwater; alluvial fan; specific discharge; peak delay analysis; field experiment; heat extraction rate; snow melting; geothermal energy

\section{Introduction}

Ground temperatures are the result of the thermal energy balance between the downward heat flux from solar radiation and the upward flux from the Earth's interior [1]. Generally, the ground temperature is almost equal to or several Kelvin higher than the average outdoor temperatures at a given location but is much less variable. This stability can be confirmed in any location in the world during all seasons in each year, indicating a degree of thermal enthalpy underground and potential for renewable energy utilization. The thermal energy can be extracted in various ways, such as pumping groundwater and heat pump systems. Heat pipe technology is also utilized for underground thermal energy.

A heat pipe is an excellent thermal energy device that works on the principles of heat conduction and phase transition to effectively transfer thermal energy [2]. Heat pipes can quickly transfer heat from one point to another using a two-phase flow schema and have a high thermal conductance [3]. A heat pipe consists of a tube with three sections: the evaporator and adiabatic and condenser sections, including a thermal dynamic working fluid. Heat pipes are applied in various products, such as heat exchangers [4] and electronic cooling devices [5]. Figure 1 below shows a schematic example of a groundsource heat pipe below a pavement for snow melting. A ground-source heat pipe is a thermosyphon heat pipe used for heat extraction from the ground, where there is relatively stable temperature [6]. The evaporator section is installed inside the borehole. The geothermal energy is extracted through the evaporation of the working fluid and transported 
upward to the condenser due to the temperature difference between the condenser and the evaporator [3]. At the condenser, the energy is dissipated to the heat sink (for example, snow on road surface which is then melted) and then the condensate returns to the evaporator by gravity to be heated again by the ground heat energy, consequently creating a cyclic process of evaporation and condensation [7].

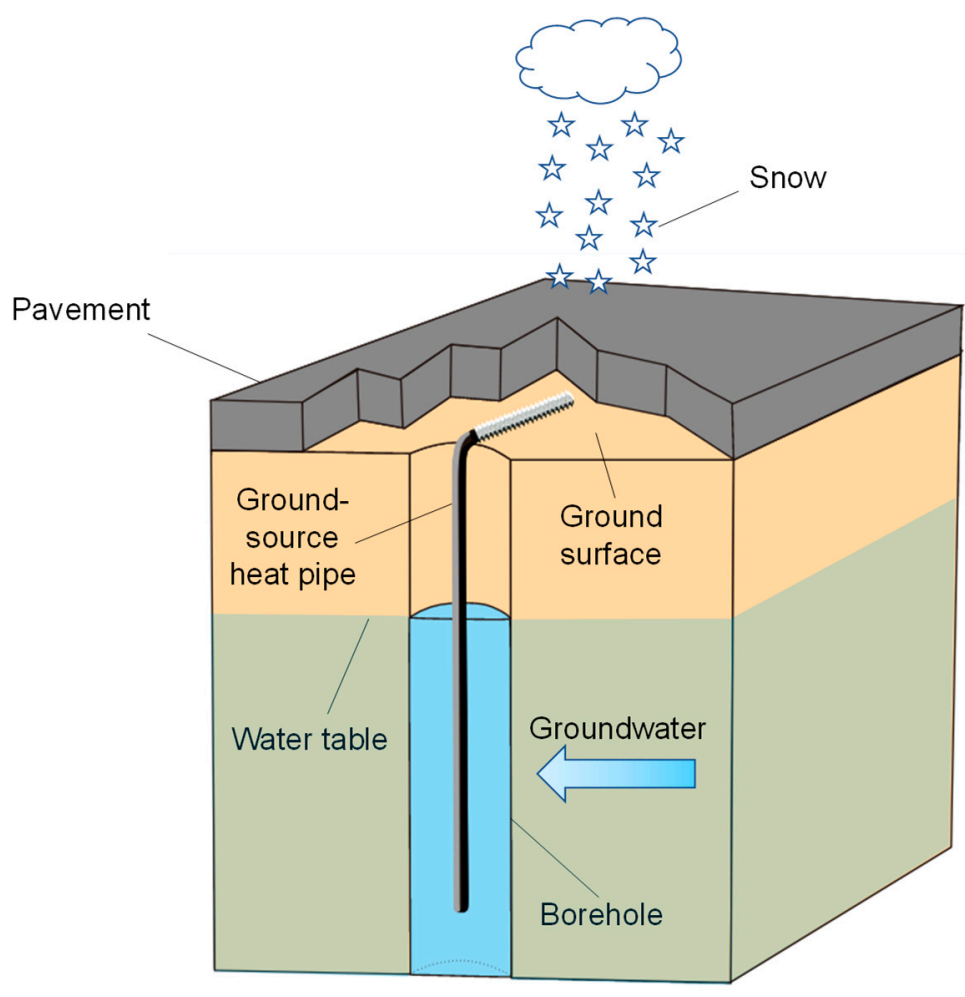

(a)



(b)



(c)

Figure 1. A schematic of ground-source heat pipe system for snow melting (a) with two example photos: (b) ground-source heat pipe for this study and (c) snow melting on a parking lot, Sapporo, Japan.

Considering that ground temperatures are higher and more stable in winter than outside temperatures, ground-source heat pipes are used mainly for road heating in areas of snowfall. The heating systems work in winter to melt snow and stop in other seasons autonomously without other energy sources, such as electricity. Thus, the systems are recognized not only as maintenance-free, but also as a renewable energy system contributing to a reduction in future carbon emissions [6]. Despite their advantages, ground-source heat pipe systems are still not popular compared with other conventional systems, such as electric heaters and gas boilers. A practical problem of ground-source heat 
pipe systems is the capital cost, including borehole construction and heat pipe installation. In Japan, as an example, the practical design recommends the installation of three heat pipes in one borehole for snow melting in an area of approximately $2 \mathrm{~m}^{2}(3 \mathrm{~m} \times 0.7 \mathrm{~m})$, resulting in $>10,000$ USD as the capital cost of a ground-heat pipe system for a land size equivalent to the parking space for one car. This capital cost is not necessarily reasonable because the payback time compared with a fossil fuel system might be more than ten years. Thus, it is desirable to reduce the capital cost of these systems, considering the potential of heat extraction rates under different conditions of heat transfer in the ground.

In practice, heat energy is assumed to be transferred from soils surrounding a borehole to heat pipes mainly by heat conduction, resulting in limited heat extraction in soils with low effective thermal conductivity. To reduce the capital cost of ground-source heat pipe systems, the authors expected that another heat transfer process by groundwater-advection heat flux could enhance the thermal performance of heat pipes in a typical site where groundwater flows actively toward the borehole. The advection effect has been validated in many theoretical studies $[8,9]$ and reported in field studies $[7,10]$. However, few studies have demonstrated field evidence of enhancement of ground-source heat pipe systems with this method.

The purpose of this study was to perform in situ experiments of ground-source heat pipes to show field evidence of enhancing heat pipe efficiency due to groundwater. For this purpose, this study conducted in situ experiments at two sites of contrasting groundwater flow in an alluvial fan of Toyohira River, Sapporo, Japan. Sapporo City is the largest city in the northern part of Japan. Snow melting on roads, pavements, and around buildings is required in winter, but fuel costs for heating are problematic. In topographic terms, in an alluvial fan, the land slope is large and thus groundwater flows actively, as compared with other topography. Furthermore, the river often loses surface water when flowing through the fan, resulting in a focused recharge of the groundwater [11]. In this study, one test site was located near the losing section of the river discharge for high groundwater velocity, as evaluated by the peak delay analysis. Another site was on the lowland adjacent to the fan toe, where the ground surface is almost flat and the groundwater flow is negligible. This study conducted field testing for potential extraction rates of a thermosyphon heat pipe device.

\section{Methodology}

\subsection{Site Description}

Figure 2 shows an alluvial fan of Toyohira River, Sapporo, in Hokkaido, the most northern island of Japan. Sapporo City is the largest city in the northern part of Japan, with a population of almost two million. The climate is subarctic, with average monthly temperatures in winter, December to March, between -3.2 and $0.9^{\circ} \mathrm{C}$. Total depth of snowfall during these four months reaches about nine meters. For winter transportation in the urbanized city, snow melting is required on roads, pavement, and around buildings. Many snow melting systems are based on fossil fuels and electricity, but their operation costs have become problematic, especially in recent decades as the energy market prices have increased. 


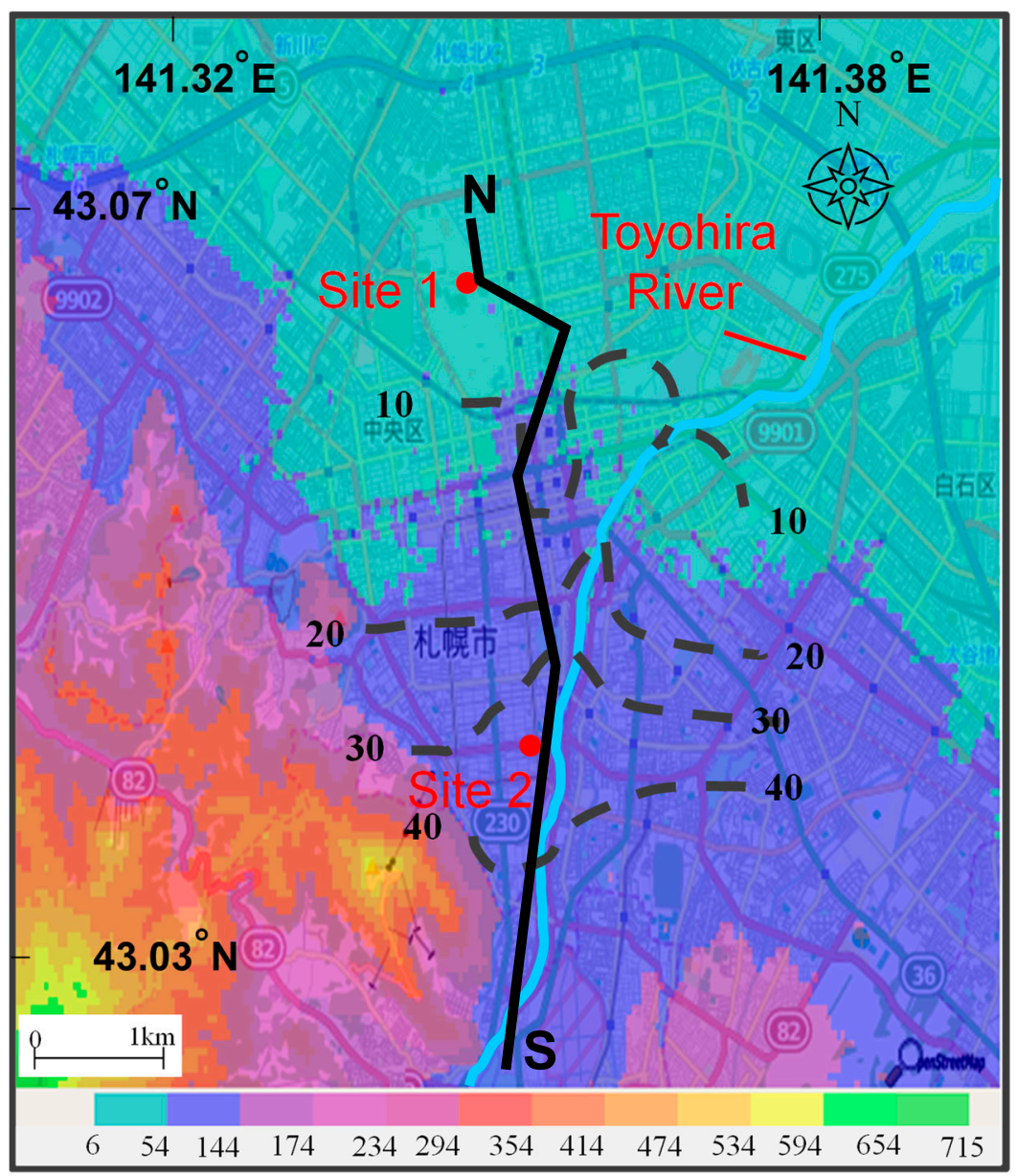

Figure 2. Site location for field experiments on a ground-elevation map (@ OpenStreetMap contributors) [12]. The edge of blue areas denotes the topographic boundary of an alluvial fan of Toyohira River. Dashed lines denote groundwater-table elevation contours from 10 to $40 \mathrm{~m}$ above mean sea level (m. amsl), modified from [13]. The black bold line is for a geologic cross-section in Figure 3.

The alluvial fan was formed with a radius of $\sim 7 \mathrm{~km}$ and an area of $\sim 31 \mathrm{~km}^{2}$ by the depositional process of the river flowing through what is now the heart of the city. The topographic slope is over several percentages in most areas of the fan and becomes less than $1 \%$ in the lowland areas. A description of the hydrogeology of the alluvial fan is summarized in a previous report [14]. Figure 3 shows a geologic cross-section along the S-N center line of the alluvial fan. This figure was modified from a previous study [15]. Tertiary rocks occur beneath the riverbed at the fan head, but the fan basement suddenly inclines northward to a depth of several hundred meters. Various Quaternary sediment units underlie the central to distal parts of the fan, with a thickness of hundreds of meters. The unconsolidated formation is classified hydrogeologically into Aquifers I-IV. The deepest aquifer, Aquifer IV, is composed of alternating clay, sand, and gravelly layers deposited fluvially before the alluvial fan developed. The Aquifer III (Pleistocene) and Aquifer II (Holocene) units consist mainly of alluvial fan gravel deposits, i.e., poorly sorted sandy gravel sediments. The boundary between Aquifer II and III is not obvious, and the total thickness of the gravel aquifers is more than $100 \mathrm{~m}$ at the middle of the fan. This study focused on Aquifer II for heat extraction by ground-heat pipes that were $20 \mathrm{~m}$ in length, which is typical for commercial products in Japan. Aquifer I is distributed only near the ground surface in the fan toe and consists of fine materials related to the fan recession. Figure 3 shows the aquifer units, water table level, and the potentiometric head contours in the cross section. In the upper fan $(<6 \mathrm{~km}$ in distance), the hydraulic head decreases in 
the downstream and downward directions, reflecting the three-dimensional groundwater flow system.
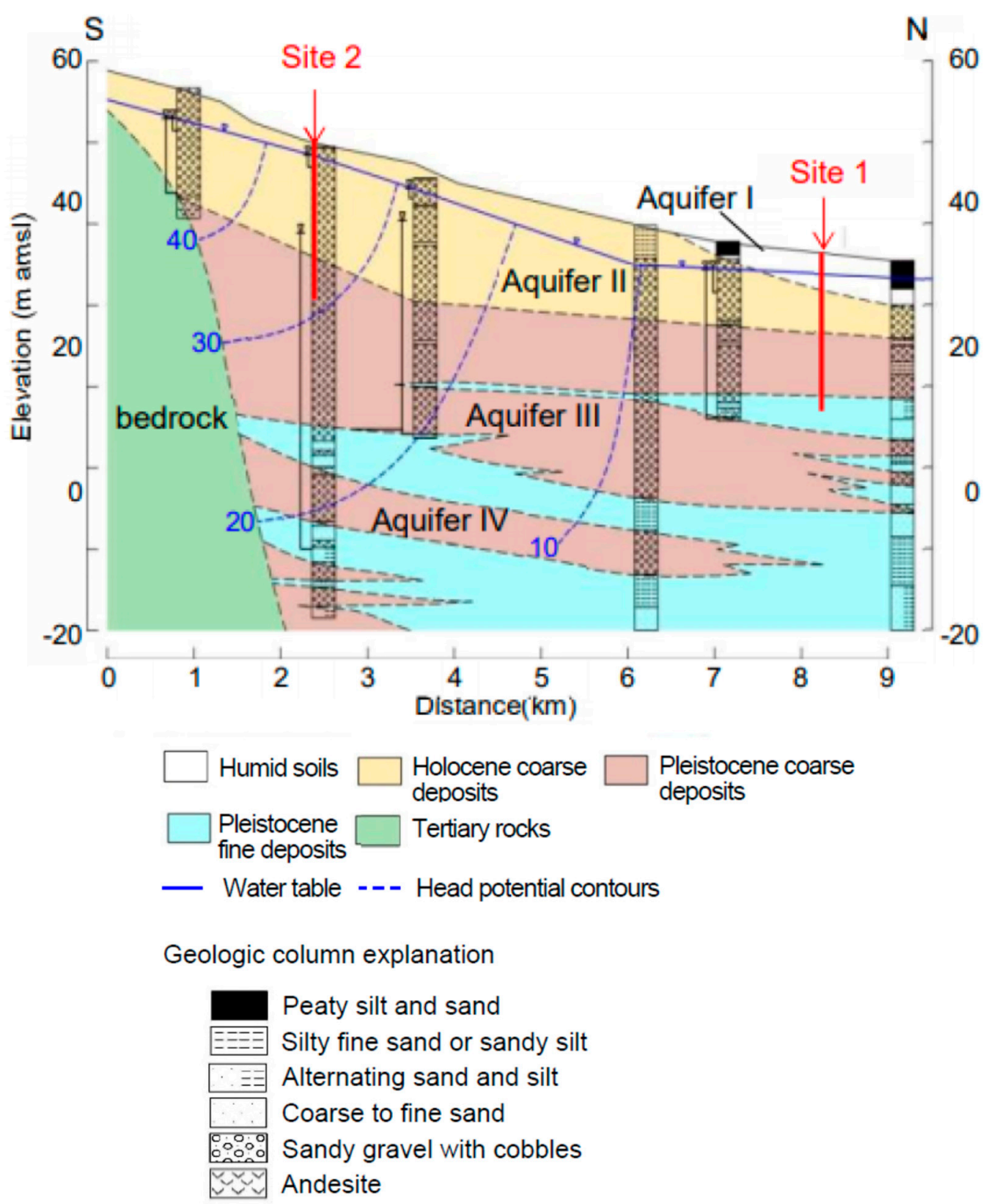

Figure 3. Hydrogeologic cross section along the S-N direction along the black line in Figure 2, modified from [15].

Figures 2 and 3 also show two experiment sites: Site 1 near the fan toe $\left(43.067^{\circ} \mathrm{N}\right.$ and $\left.141.320^{\circ} \mathrm{E}\right)$, and Site 2 in the fan apex $\left(43.030^{\circ} \mathrm{N}\right.$ and $\left.141.383^{\circ} \mathrm{E}\right)$, respectively. At Site 1 , a previous study [15] conducted thermal response tests at the same site, finding that groundwater velocity is at a negligible rate, less than $0.1 \mathrm{~m} / \mathrm{d}$, because of the flat topography. In contrast, groundwater at Site 2 flows actively, because the topography is steeper than at Site 1 . In addition, Site 2 is located near a losing section of the river discharge, as determined in the numerical simulation based on synoptic discharge surveying [16]. Figure 4 shows the temperature observations of groundwater at a depth of $7 \mathrm{~m}$ in Site 1 and $12 \mathrm{~m}$ in Site 2, respectively. The groundwater temperature at Site 2 was seasonally variable, and the peak was delayed relative to the peak of the river temperatures. In contrast, the 
temperature of groundwater measured at Site 1 was almost constant, indicating negligible groundwater flow at the site.

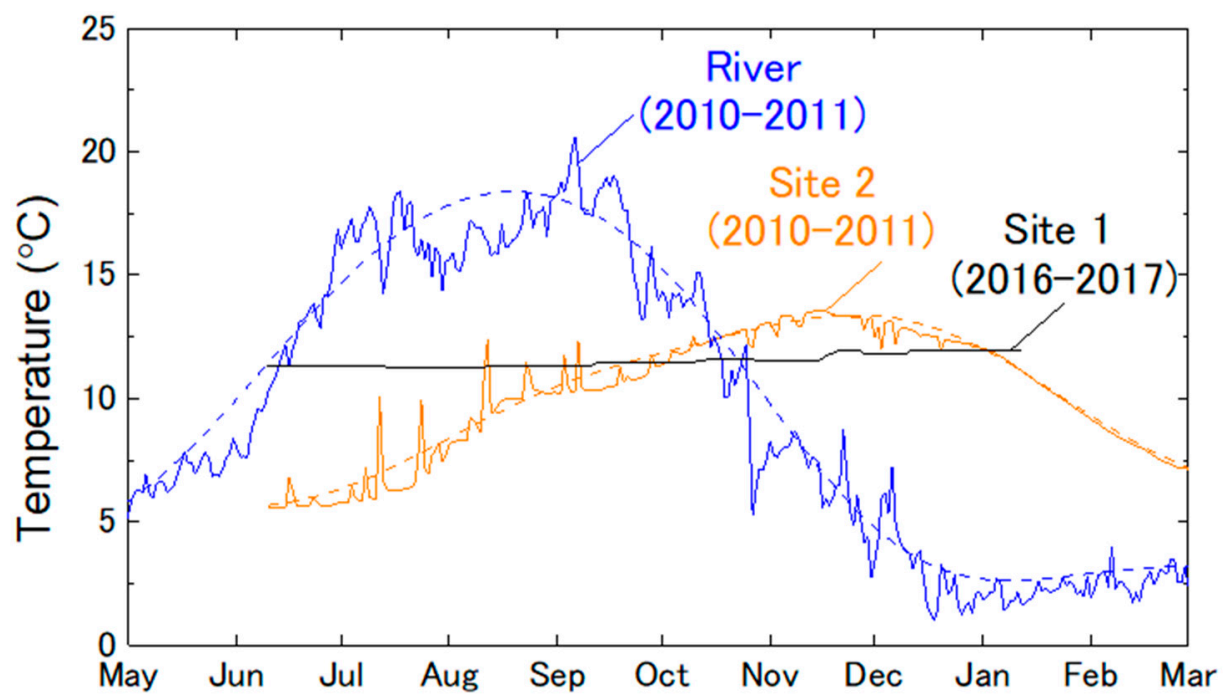

Figure 4. Variations in the temperature observations of groundwater at Site 1 and Site 2, and of surface water in the Toyohira River. The observation periods were between May 2010 and March 2011 for Site 2 and the river, and between June 2016 and February 2017 for Site 1.

In this study, an analysis of peak delay in temperatures by heat transfer from the river to the groundwater was conducted to estimate the specific discharge of groundwater, i.e., Darcy velocity [17]. The records of river temperatures near Site 2 until March 2011 were publicly available [18]. The author also measured groundwater temperatures in a borehole at Site 2 from June 2010 [19] to the present. Here, the temperature data between June 2010 to March 2011 were used for the analysis of peak delay in temperatures. This study conducted a filtering pass of frequency between 0.01 and $1001 / \mathrm{s}$, indicating the long-term changes, with a temperature peak on 25 November 2010 at Site 2 and on 19 August 2010 in the river; the peak delay was $\Delta T=98.1$ days. The specific discharge $u$ of groundwater from the river to Site 2 was evaluated from:

$$
u=\frac{C_{\mathrm{s}} \rho_{\mathrm{s}}}{C_{\mathrm{w}} \rho_{\mathrm{w}}} v_{\mathrm{T}}=\frac{C_{\mathrm{s}} \rho_{\mathrm{s}}}{C_{\mathrm{w}} \rho_{\mathrm{w}}} \frac{L}{\Delta T}
$$

where $C_{\mathrm{s}} \rho_{\mathrm{s}}$ and $C_{\mathrm{w}} \rho_{w}$ are the volumetric heat capacity of the soils, assumed to be 3.0 MJ $/\left(\mathrm{K} \mathrm{m}^{3}\right)$ for the unconsolidated sediments in this study, and $4.2 \mathrm{MJ} /\left(\mathrm{K} \mathrm{m}^{3}\right)$ for groundwater, respectively; $v_{\mathrm{T}}$ is the peak velocity $[\mathrm{m} / \mathrm{d}]$, equal to the distance from the river to the observation well, $L[\mathrm{~m}]$, and divided by the peak delay $\Delta T$ [d]. At Site 2, the distance $L$ was $42 \mathrm{~m}$, and thus the specific discharge $u$ was evaluated at $1.0 \mathrm{~m} / \mathrm{d}$. The value was higher than $10^{-5} \mathrm{~m} / \mathrm{s}=0.86 \mathrm{~m} / \mathrm{d}$, meeting the criteria of specific discharge for an advection effect in shallow geothermal utilization [20]. The discharge was an average during August to December 2011 as the period for heat transfer from the river to Site 2; the value might be variable in other periods according to the water levels in the river and groundwater. The temperature measurements were also conducted in a borehole at Site 1 between June 2016 and January 2017, indicating an unclear peak in the groundwater temperatures. This means that groundwater flows were not apparent in the flat area of small hydraulic gradients.

\subsection{Field Experiment Setting}

This study conducted field experiments by using the most popular heat pipe product in Japan, with an inner diameter of $25 \mathrm{~mm}$ and an outer diameter of $28 \mathrm{~mm}$ (Kowa Co., Ltd., Niigata, Japan). R134A fluid filled the heat pipes. Single and double heat pipes were 
tested in the experiment; each pipe had an upper section of $3 \mathrm{~m}$, made of SUS304/SUS316 with a corrugated structure for efficient condensation or heat dissipation. The $20 \mathrm{~m}$ lower section in this case was installed into a borehole, which was used for heat extraction from the ground by evaporation.

The field experiments were set up schematically as shown in Figure 5. Figure 5 also shows a photo of the experiment at Site 2. At the experiment site, the heat pipe denoted as (I) was tested for single heat pipe cases, while for double heat pipe cases, both heat pipes (I) and (II) were tested in a borehole of each site. The borehole depths were 64 and $34.5 \mathrm{~m}$ at Sites 1 and 2, respectively. An inner diameter of $75 \mathrm{~mm}$ and outer diameter of $77 \mathrm{~mm}$ were common to the two boreholes. The water table depth was $4.5 \mathrm{~m}$ at Site 1 and $7.5 \mathrm{~m}$ at Site 2 . Heat flow to the borehole wall was mainly by conduction at Site 1 and by groundwater advection in Site 2. The evaporator section length was $14.7 \mathrm{~m}$ at Site 1 and $11.7 \mathrm{~m}$ at Site 2. The adiabatic section was between the water table depth and the condenser section. At both sites, the condenser section length was $3 \mathrm{~m}$ and placed above the ground surface in a thermally insulated PVC tube $(40 \mathrm{~mm}$ diameter. The adjustable slope of the condenser section was set at $2 \%$ in this study.

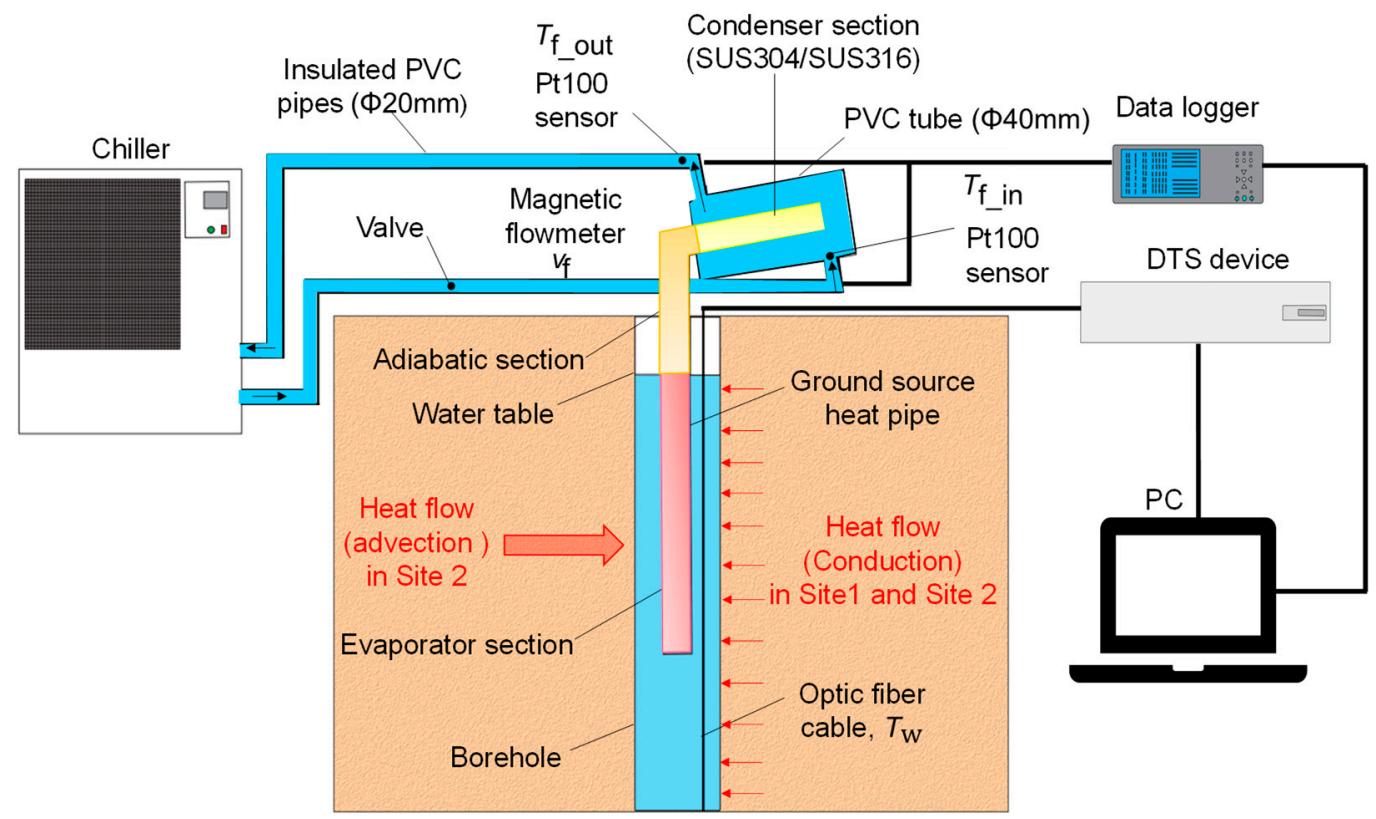

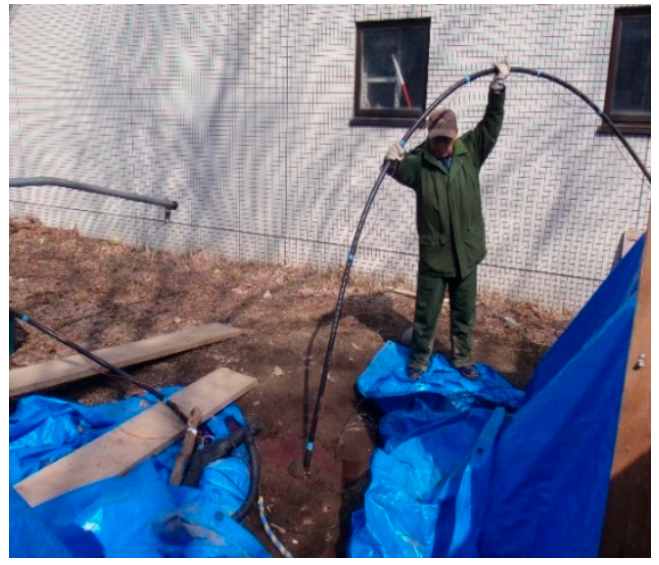

(b) (a)

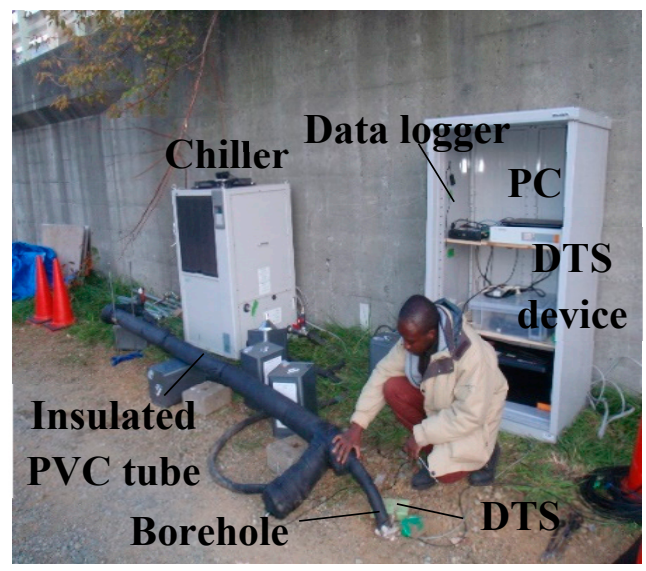

(c)

Figure 5. Schematic of the field experiment setup for a single heat pipe (a) with two explanatory pictures; heat pipe installation (b) and field experiment set up at Site 2 (c). In (a), the heat pipe is divided in different colors: red for the evaporator section, orange for the adiabatic section, and yellow for the condenser section. $T_{\mathrm{f}_{-} \text {out }}, T_{\mathrm{f} \_ \text {in }}$ and $T_{\mathrm{W}}$ are the outlet and inlet temperatures of the circulation fluid in the pipe covering the heat pipe, and the water in the borehole, respectively. 
The temperature of water in the borehole $T_{w}$ was recorded by a distributed temperature sensor (DTS) at $0.5 \mathrm{~m}$ intervals. This sensor was an optic fiber cable SKFVP13L404CC140 of NK Systems, Co., Ltd., Tokyo, Japan with an accuracy of $0.5^{\circ} \mathrm{C}$. The sensor data were observed by the DTS device, N4385A-008, of A.P. Sensing, Co., Ltd., Herrenberg, Germany. The thermally insulated PVC tube was connected to the chiller via the insulated inlet and outlet pipe connections. The chiller PCU-SL10000 (Apiste Co., Ltd., Osaka, Japan), with an output power of $4 \mathrm{~kW}$, was used in this experiment to control the brine set temperature $T_{\text {in }}$ and flowrate $v_{\mathrm{f}}$ of the fluid circulating around the condenser section in the tube. The flowrate was then adjusted by a valve along the inlet pipe connection. The fluid circulation set temperatures $T_{\text {in }}$ selected for the field experiments were $-5,0$, and $5{ }^{\circ} \mathrm{C}$.

The inlet and outlet temperatures of the circulating fluid were measured by Pt100 sensors (Class A), with an accuracy of $0.1^{\circ} \mathrm{C}$. In the double heat pipes, the inlet temperatures for heat pipes (I) and (II) were measured by one Pt100 sensor, while the outlet temperatures were measured individually. The flowrate was measured by ND-type flow sensors: ND10NATAAA-RC and ND20-NATAAA (Aichi Tokei Denki Co., Ltd., Nagoya, Japan), with an accuracy of $0.2 \%$. All field experiment data were recorded per minute by the PC and the data logger (Hioki 8424-50, Hioki E. E. Co., Ltd., Nagano, Japan). The observed heat transfer rates with time $Q$ of the heat pipes were calculated based on the cooling temperatures of the brine (ethylene glycol at $40 \%$ concentration) circulating in the annular tube:

$$
Q=C_{\mathrm{f}} \rho_{\mathrm{f}} v_{\mathrm{f}} v T=C_{\mathrm{f}} \rho_{\mathrm{f}} v_{\mathrm{f}}\left(T_{\mathrm{f} \_ \text {out }}-T_{\mathrm{f} \_ \text {in }}\right)
$$

where the volumetric heat capacity $\mathrm{C}_{\mathrm{f}} \rho_{\mathrm{f}}$ of the fluid (brine) was $3.55 \mathrm{MJ} /\left(\mathrm{K} \mathrm{m}^{3}\right)$ at $-5{ }^{\circ} \mathrm{C}$, $3.59 \mathrm{MJ} /\left(\mathrm{K} \mathrm{m}^{3}\right)$ at $0{ }^{\circ} \mathrm{C}$, and $3.65 \mathrm{MJ} /\left(\mathrm{K} \mathrm{m}^{3}\right)$ at $5{ }^{\circ} \mathrm{C} ; v_{\mathrm{f}}$ represents the flow rate of the circulating brine, which was set at $12 \mathrm{~L} / \mathrm{min}$. $T_{\mathrm{f}_{-} \text {out }}$ and $T_{\mathrm{f}_{-} \text {in }}$ are the outlet and inlet temperatures of the fluid circulating in the annular pipe per minute, respectively. $\Delta T$ is the temperature difference between $T_{\mathrm{f} \_ \text {out }}$ and $T_{\mathrm{f} \_ \text {in }}$.

The testing durations were different between 1440 to $5760 \mathrm{~min}$, according to the site situation. However, the heat transfer rates $Q$ were commonly converged after several hours in each test, as described later, in Figure 5a. Thus, the average of $Q$ after half a day (720 $\mathrm{min}$ ) was calculated in each test condition as a value in a steady state condition. The steady state condition was also confirmed by using the filter approach, based on the ratio of variance [21]; the results were omitted for the paper restriction. The uncertainty in the observed heat transfer rate was calculated as the square root of each component in Equation (1), where $\delta Q$ is the uncertainty in $\bar{Q}, \delta C_{\mathrm{f}}$ is the uncertainty in the fluid heat capacity, $\delta \rho_{\mathrm{f}}$ is the uncertainty in the fluid density, $\delta v_{\mathrm{f}}$ is the uncertainty in the flow rate, and $\delta \Delta T$ is the uncertainty in $\Delta \mathrm{T}$. The uncertainties in $\delta \mathrm{C}_{\mathrm{f}}, \delta \rho_{\mathrm{f}}$, and $\delta v_{\mathrm{f}}$ were considered negligibly small, and therefore not included in the calculation for the uncertainty in the observed heat transfer rate in Equation (3):

$$
\frac{\delta Q}{Q}=\sqrt{\left(\frac{\delta C_{\mathrm{f}}}{C_{\mathrm{f}}}\right)^{2}+\left(\frac{\delta \rho_{\mathrm{f}}}{\rho_{\mathrm{f}}}\right)^{2}+\left(\frac{\delta v_{\mathrm{f}}}{v_{\mathrm{f}}}\right)^{2}+\left(\frac{\delta \Delta T}{\Delta \bar{T}}\right)^{2}} \cong \sqrt{\left(\frac{\delta \Delta T}{\Delta \bar{T}}\right)^{2}}=\frac{\delta T_{\mathrm{f} \_ \text {out }}+\delta \mathrm{T}_{\mathrm{f} \_ \text {in }}}{\Delta \bar{T}}
$$

where $\delta T_{\mathrm{f}_{\text {oout }}}$ and $\delta T_{\mathrm{f}_{-} \text {in }}$ are the standard deviations from the measurements of the inlet and the outlet temperatures, and $\Delta \bar{T}$ is the average temperature difference between the outlet and inlet temperatures. To reduce the standard deviations of temperature fluctuations to within $0.1^{\circ} \mathrm{C}$, a three-minute moving average was used for the inlet and outlet temperatures. To calculate the uncertainty in $\bar{Q}$ for double heat pipes, the individual uncertainties for heat pipe (I) and (II) were averaged to give the uncertainty for the total $\bar{Q}$ for both heat pipes. The field experiments were conducted from 11 March 2020 to 25 June 2020 at Site 1 and from 21 November 2019 to 24 December 2019 at Site 2, as summarized in Table 1. 
Table 1. A summary of the experiment configurations and results.

\begin{tabular}{|c|c|c|c|c|c|c|}
\hline Site & Single/Double & Start Date & End Date & $\bar{T}_{\mathrm{f} \_ \text {in }}\left({ }^{\circ} \mathrm{C}\right)$ & $\bar{Q}(\mathbf{k W})$ & $\frac{\delta Q}{Q}(\%)$ \\
\hline \multirow[t]{6}{*}{ Site 1} & Single & 10 June 2020 & 13 June 2020 & -5.00 & 0.79 & 17 \\
\hline & & 18 June 2020 & 19 June 2020 & -0.52 & 0.52 & 13 \\
\hline & & 22 June 2020 & 25 June 2020 & 4.66 & 0.23 & 16 \\
\hline & Double & 28 April 2020 & 01 May 2020 & -5.36 & 0.86 & 18 \\
\hline & & 02 May 2020 & 04 May 2020 & -0.37 & 0.65 & 15 \\
\hline & & 11 March 2020 & 14 March 2020 & 4.58 & 0.48 & 25 \\
\hline \multirow[t]{6}{*}{ Site 2} & Single & 21 November 2019 & 24 November 2019 & -5.08 & 0.75 & 26 \\
\hline & & 26 November 2019 & 29 December 2019 & -0.32 & 0.67 & 27 \\
\hline & & 03 December 2019 & 06 December 2019 & 4.44 & 0.44 & 52 \\
\hline & Double & 24 December 2019 & 27 December 2019 & -5.57 & 1.25 & 22 \\
\hline & & 17 December 2019 & 20 December 2019 & -0.59 & 1.17 & 23 \\
\hline & & 21 December 2019 & 24 December 2019 & 4.43 & 1.00 & 28 \\
\hline
\end{tabular}

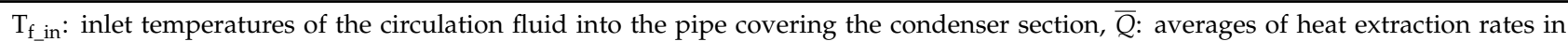
Equation (2), and $\frac{\delta Q}{Q}$ : relative uncertainty of heat extraction rates in Equation (3).

\subsection{Comparison with Theoretical Potential for Heat Transfer}

This study compared measured $\bar{Q}$ with theoretical potentials for heat extraction of $Q^{*}$ by ground-source heat pipes. The potential $Q^{*}$ for heat extraction by a single heat pipe was estimated as below [22], where $\bar{T}_{\mathrm{e}}$ and $\bar{T}_{\mathrm{c}}$ are the average evaporator and condenser surface temperatures, $R_{\mathrm{HP}}$ is the total thermal resistance of the ground-source heat pipe, and $Q_{\max }$ is the maximum heat extraction rate.

$$
Q^{*}=\frac{\bar{T}_{e}-\bar{T}_{c}}{R_{H P}} \leq Q_{\max }
$$

$\bar{T}_{\mathrm{e}}$ was calculated as an average from Equation (5) below, where $T_{\mathrm{e}}$ is the evaporator surface temperature, $T_{\mathrm{W}}$ is the temperature of water in the borehole, $Q$ is the measured heat extraction rates, and $h$ is the heat transfer coefficient due to natural convection where the Nusselt number that was used assumed a condition of fully developed natural convection inside the water-filled borehole [23].

$$
T_{\mathrm{e}}=T_{\mathrm{w}}-Q / h A_{\mathrm{e}}
$$

$\bar{T}_{\mathrm{c}}$ is the average condenser surface temperature calculated from Equation (6), where $T_{\mathrm{C}}$ is the condenser surface temperature, $T_{\mathrm{bulk}}$ is the temperature of fluid circulating in the PVC tube, which was used as a heat sink, $Q$ is the measured heat transfer rate, $h_{\text {cond }}$ is the heat transfer coefficient due to forced flow in the PVC tube, and $A_{\mathrm{c}}$ is the area of the condenser section of the heat pipe. In Equation (6), the Nusselt number that was utilized in the analysis to determine $h_{\text {cond }}$ assumed a thermally and simultaneously developing flow around the condenser of the heat pipe in the PVC tube [24].

$$
T_{\mathrm{c}}=T_{\text {bulk }}-Q / h_{\text {cond }} A_{\mathrm{c}}
$$

To study the performance of this ground-source heat pipe, Imura's correlation was employed as a nucleate boiling heat transfer coefficient $h_{\mathrm{e}}$ for the analysis. This correlation was specially developed for thermosiphon heat pipes such as the ground-source heat pipe used in the field experiment, indicating an excellent accuracy at high filling ratios [25]. In Equation (7), $\rho_{1}$ is the liquid density, $\lambda_{l}$ is the thermal conductivity of the liquid, $C p_{1}$ is the liquid heat capacity, $g$ is the acceleration due to gravity, $q_{\mathrm{e}}$ is the heat flux at the evaporating area, $\rho_{v}$ is the density of the vapor, $L$ is the latent heat, $\mu_{1}$ is the dynamic viscosity of the liquid, $P_{\text {in }}$ is the ground-source heat pipe internal pressure, and $P_{\mathrm{o}}$ is the ambient pressure.

$$
h_{\mathrm{e}}=0.32 \frac{\rho_{1}^{0.65} \lambda_{1}^{0.3} C p_{1}^{0.7} g^{0.2} q_{\mathrm{e}}^{0.4}}{\rho_{\mathrm{v}}^{0.25} L^{0.4} \mu_{1}^{0.1}}\left(P_{\text {in }} / P_{\mathrm{o}}\right)^{0.3}
$$


Film-wise condensation was assumed to be taking place in the model of this heat pipe. The Nusselt heat transfer coefficient is the most used to predict condensation heat transfer coefficients in laminar and wavy-laminar films [26]. Thus, in this model, the Nusselt correlation for condensation was selected to calculate $h_{\mathrm{c}}$, as shown in Equation (8) for the heat transfer analysis in the of the ground-source heat pipe. In Equation $(8), \lambda_{1}$ is the thermal conductivity of the liquid, $\rho_{1}$ is the density of the liquid, $g$ is the acceleration due to gravity, $L$ is the latent heat, $\mu_{1}$ is the dynamic viscosity of the liquid, $\Delta T_{\mathrm{c}}$ is the temperature difference between the vapor temperature and wall temperature at the condenser section of the ground-source heat pipes, and $l_{\mathrm{c}}$ is the condenser length section of the ground-source heat pipe.

$$
h_{\mathrm{c}}=0.943\left\{\lambda_{1}^{3} \rho_{1}^{2} g \frac{L}{\left(\mu_{1} \Delta T_{\mathrm{c}} l_{\mathrm{c}}\right)}\right\}^{0.25}
$$

The total thermal resistance of the ground-source heat pipe $R_{\mathrm{HP}}$ was then calculated as shown below, where $A_{\mathrm{e}}$ is the area of the evaporator and $A_{\mathrm{C}}$ is the area of the condenser.

$$
R_{\mathrm{HP}}=\frac{1}{A_{\mathrm{e}} h_{\mathrm{e}}}+\frac{1}{A_{\mathrm{c}} h_{\mathrm{c}}}
$$

In a ground-source heat pipe, the vapor flows from the evaporator to the condenser, forming a continuous cyclic flow from the condenser to the evaporator. However, the performance of the ground-source heat pipe is limited by various heat transport limitations. The main heat transport limitation on ground-source heat pipes is the entrainment limit. This type of heat transport limitation depends on geometric dimensions for example diameter, and evaporator length, working fluid fill charge, and radial heat flux. Thus, an entrainment limit occurs for high fill charges, and high axial heat flows, but small radial evaporator heat fluxes [27]. The high axial heat flows cause a high relative velocity between the counter-current vapor and liquid flows and consequently an increase in the shear stress at the vapor/liquid interface. Thus, an instability of the liquid flow is created, which leads to an entrainment of the liquid. The entrained liquid is transported to the condenser by the vapor and is collected there. The high shear stresses can also cause the returning condensate flow to be completely stopped. Then, the condensate flow breaks up at the flooding point. In any case, the intense entrainment or flooding causes an insufficient liquid supply to the evaporator. This leads to local dry out and ultimately to a complete dry-out of the evaporator [27].

In this work, the entrainment limit was determined by Equation (10) and Equation (11) as called the Imura's method [28], where $\phi$ is the Kutateladze number.

$$
\begin{gathered}
q_{\text {ent }}=L\left\{\sigma g \rho_{v}^{2}\left(\rho_{1}-\rho_{v}\right)\right\}^{0.25} \phi \\
\phi=\left(0.16\left[1-\exp \left\{-\left(\frac{D_{\mathrm{i}}}{l_{\mathrm{e}}}\right)\left(\frac{\rho_{\mathrm{l}}}{\rho_{v}}\right)^{0.13}\right\}\right]\right)
\end{gathered}
$$

The maximum heat extraction rate of the heat pipe was determined by using Equation (12).

$$
Q_{\max }=q_{\mathrm{ent}} A_{\mathrm{e}}
$$

From Equation (10) to Equation (12), $L$ is the latent heat, $\sigma$ surface tension, $g$ is the acceleration due to gravity, $\rho_{\mathrm{v}}$ is the vapor density, $\rho_{1}$ is the liquid density, $D_{\mathrm{i}}$ is the inner diameter of the ground-source heat pipe, $l_{\mathrm{e}}$ is the length of the evaporator section, and $A_{\mathrm{e}}$ is the area of the evaporator section.

\section{Results and Discussion}

Table 1 summarizes the conditions for the field experiments, i.e., $\bar{T}_{\mathrm{f} \_ \text {in }}$, and the results, i.e., $\bar{Q}$, and $\delta Q / Q$, which symbolize the fluid inlet temperatures, heat extraction rates, and uncertainty in the heat extraction rates, respectively. Figure 6a shows an example 
of $\Delta T, T_{\mathrm{f} \_ \text {in }}$, and $T_{\mathrm{f} \_ \text {out }}$, which depict the temperature difference and the inlet and outlet temperatures with time for a single heat pipe case at the set temperature of $-5^{\circ} \mathrm{C}$ at Site 1 . In Figure $6 \mathrm{a}, \Delta T, T_{\mathrm{f} \_ \text {in }}$, and $T_{\mathrm{f} \_ \text {out }}$ were in the transient state at around 0 to $27 \mathrm{~min}$, which afterwards indicated the steady-state condition. Figure 6a also illustrates that $\Delta T$ was always greater than $0{ }^{\circ} \mathrm{C}$ in the steady-state condition, due to the upward transport of heat energy from the evaporator to the condenser.

(a)

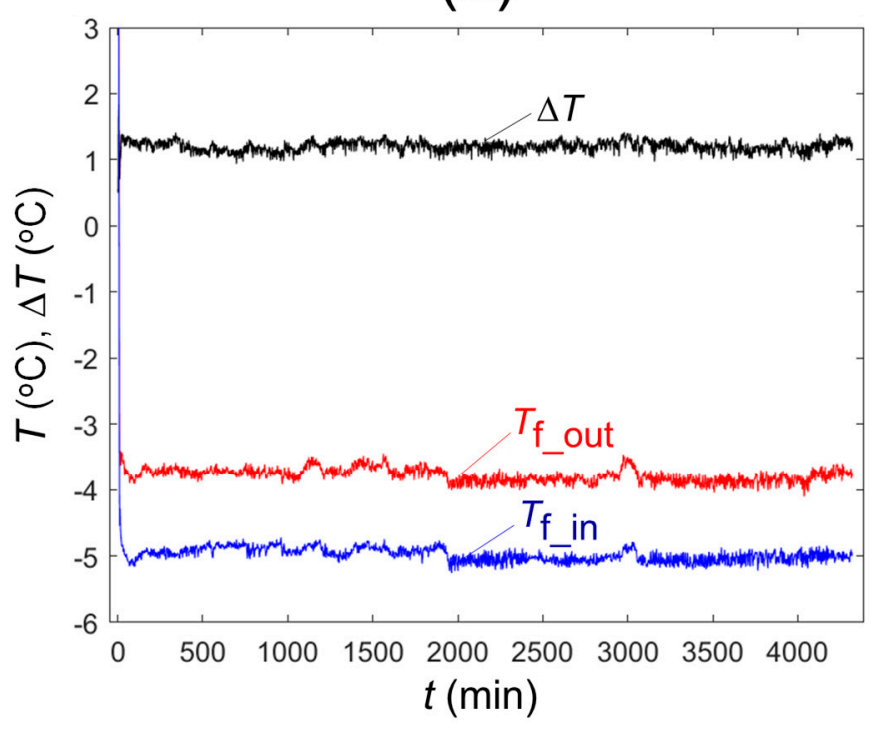

(b)

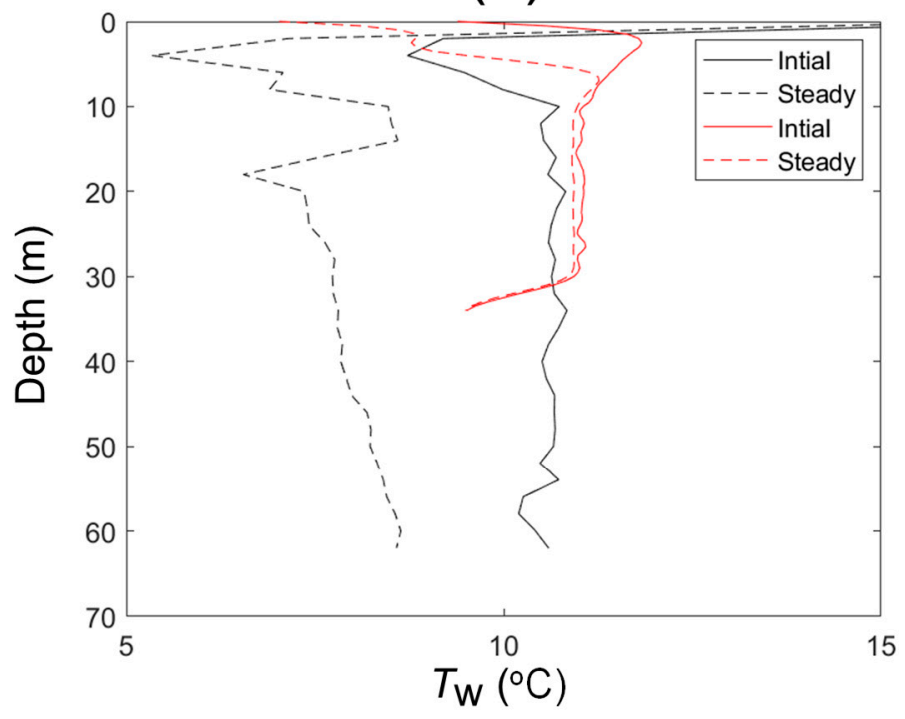

Figure 6. Example of temperature observations, testing inlet temperatures $T_{\mathrm{f}_{\text {_in }}}$, outlet temperature $T_{\mathrm{f} \_ \text {out }}$, and their difference $\Delta T$ at a set temperature $T_{\text {in }}$ of $-5{ }^{\circ} \mathrm{C}$ at Site 1 for a single heat pipe system (a) and temperature profiles with measurement depth before and during steady-state single-heat-pipe heat extraction at Site 1 and 2 (b).

Figure $6 \mathrm{~b}$ shows the ground temperature profiles at Sites 1 and 2, at the initial and steady conditions in the experiment. The initial temperatures were the average temperature over $60 \mathrm{~min}$. The temperatures depicted as steady in Figure $6 \mathrm{a}$ were the average temperature from 1400 to $4320 \mathrm{~min}$. Thus, Figure $6 \mathrm{~b}$ indicates that the ground temperature profile from the water table depth to the bottom of the borehole changed on average by $3{ }^{\circ} \mathrm{C}$ from the initial conditions in Site 1 , and $0.1^{\circ} \mathrm{C}$ on average at Site 2 . The small temperature change at Site 2 was probably due to groundwater flow, which after heat extraction by the heat pipe replenished the heat energy at the borehole wall at much faster rates than without groundwater flow, where heat was transferred to the borehole wall by conduction only, resulting in a larger temperature difference at Site 1.

Figure 7a shows $\bar{Q}$ for all cases of single ground-source heat pipes at Sites 1 and 2 . At Site $1, \bar{Q}$ varied between 0.23 and $0.79 \mathrm{~kW}$, and at Site 2 between 0.44 and $0.75 \mathrm{~kW}$. Considering the uncertainty, an enhancement of $\bar{Q}$ by groundwater flow was not observed at Site 2 for a single heat pipe. On the other hand, Figure $7 \mathrm{~b}$ shows the $\bar{Q}$ in all test cases for double heat pipes at Site 1 and Site 2. A comparison of $\bar{Q}$ between Sites 1 and 2 for double heat pipes revealed that $\bar{Q}$ at Site 2 was commonly higher than $\bar{Q}$ at Site 1, by $146 \%$ on average. 
(a)

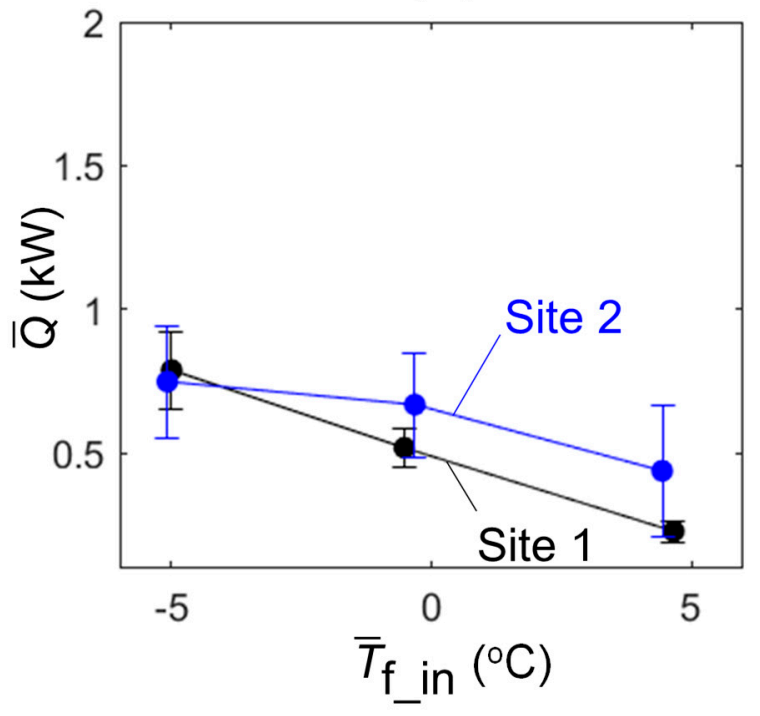

(b)

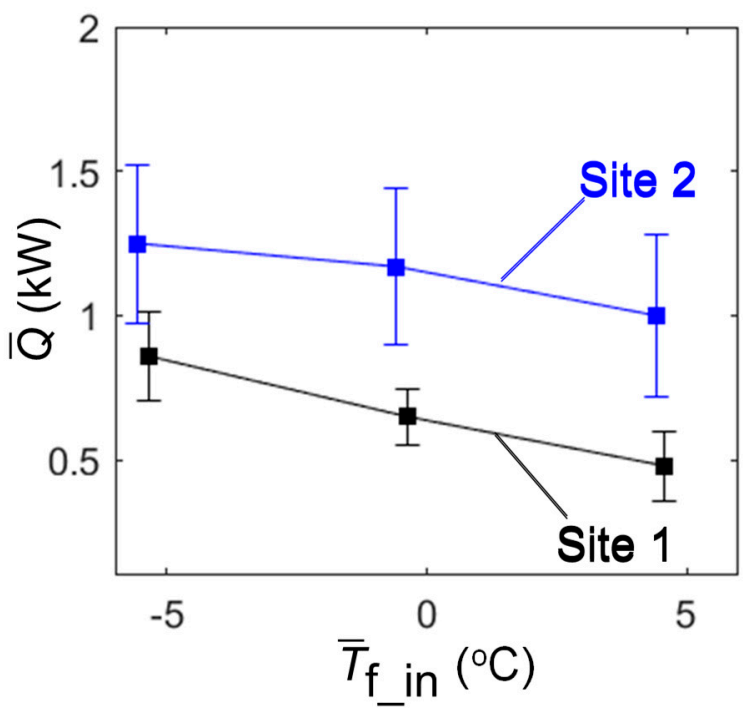

Figure 7. A comparison of heat extraction rates $\bar{Q}$ for single (a) and double heat pipes (b) against testing inlet temperatures $T_{\mathrm{f} \_ \text {in }}$ for Sites 1 and 2; the bar of each plot denotes the uncertainty $\delta Q$, calculated by Equation (3).

The small ground temperature change observed during testing at Site 2 in comparison to Site 1 indicated active groundwater flow at Site 2. The field experiment results for double heat pipes at Site 2 were reasonable, because $\bar{Q}$ was almost twice the value of $\bar{Q}$ for single heat pipes. Therefore, heat transfer by advection could yield sufficient energy for double heat pipes at Site 2. At Site 1, the field experiment results for double heat pipes were almost equal to those of single heat pipes. This limitation was because heat transfer by conduction only could not provide more than the heat extraction rates for single heat pipes. The detailed explanations will be given in a future numerical study.

Figure 8 shows the relationship between potential $Q^{*}$ and observed $\bar{Q}$. This figure indicates sufficient agreement for single heat pipes at both Site 1 and Site 2, considering measurement errors. This means that the in situ measurements revealed the potential of heat extraction rates for single heat pipes. The figure also shows double heat pipes at Site 2 , indicating sufficient groundwater flow to obtain higher potential heat extraction rates. The agreement between $Q^{*}$ and $\bar{Q}$ confirms the discussion above related to groundwater flow. In contrast, for the double heat pipes at Site 1, observed $\bar{Q}$ was smaller than potential $Q^{*}$. One reason for this difference was that heat conduction from only the ground at Site 1, characterized by negligible groundwater flow, could not yield sufficient thermal energy for extraction by double heat pipes. Another reason is that the thermal interaction of double heat pipes might reduce the heat extraction rates as compared with the potential. Thus, in a future study, calculating potential heat extraction rates by multiple ground-heat pipes could be improved by considering thermal interference.

Finally, the potential applicability of ground-source heat pipes in an alluvial fan is discussed. The heating power of snow melting systems required for public roads in this region is $250 \mathrm{~W} / \mathrm{m}^{2}$ [29]. Thus, heating power of approximately $0.5 \mathrm{~kW}$ for a snow melting area of $2 \mathrm{~m}^{2}$ by three ground-source heat pipes in one borehole is needed. Assuming a ground surface temperature of $0{ }^{\circ} \mathrm{C}$ in winter, $\bar{Q}$ was in the range 0.52 to $0.65 \mathrm{~kW}$ at Site 1 for single and double heat pipes, and $0.67 \mathrm{~kW}$ at Site 2 for single heat pipes. Although these values commonly exceeded the required $0.5 \mathrm{~kW}$, the uncertainty in $\bar{Q}$ indicated that the actual $\bar{Q}$ might not be sufficient. In contrast, $\bar{Q}$ was observed at $1.17 \mathrm{~kW}$ for double heat pipes at Site 2, which was above the required heating power of $0.5 \mathrm{~kW}$ even if uncertainty was considered. This implies that the required number of heat pipes could be reduced from three in the conventional way to two in the areas having fast velocity of groundwater. This means that the capital costs of ground-source heat pipes can be reduced by about 
$30 \%$ in an assumption that the cost is almost linearly related to the number of heat pipes. However, if the cost-effective systems are designed with two or one heat pipes, the shapes of condensers under the pavements must be modified or the fins must be added to ensure the same efficiency of snow melting as with three condensers.

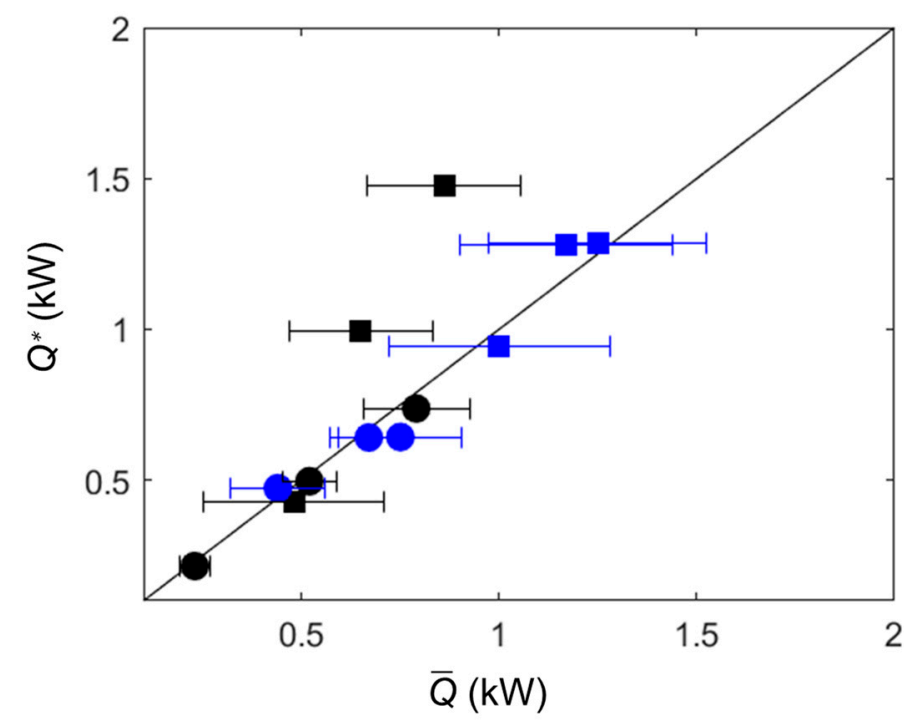

Figure 8. A relationship between the potential heat extraction rates $\bar{Q}^{*}$ and the measured heat extraction rates $\bar{Q}$ for single (circles) and double (squares) heat pipes at Site 1 (black) and Site 2 (blue). The bar of each plot denotes the uncertainty $\delta Q$, calculated by Equation (3).

The experiments assumed the set temperatures for condensation were constant at -5 , 0 , and $5{ }^{\circ} \mathrm{C}$, and the heating transfer rates were converged after several hours. It is noticed that the results of the experiments should be applied only during the winter when it is cold. Actually, the heat transfer rate $Q$ might be variable according to the air temperature and the groundwater velocity. Transient analysis of heat transfer in ground-source heat pipes will be required to evaluate the thermal performance over the year, considering the change in climate and groundwater conditions. In addition, this field study confirmed the effect of groundwater flow only in areas near Site 2. The specific discharge in Site 2 was estimated at approximately $1 \mathrm{~m} / \mathrm{d}$, and the value was found only in steep areas where rivers from the mountains enter a flat plain. Despite the limitations in this study, it is concluded that ground-source heat pipe systems can be installed less costly in specific topography for such fast groundwater flows.

\section{Conclusions}

This study demonstrates a field experiment on ground-source heat pipes in different groundwater flow effects in the alluvial fan of Toyohira River, Japan. A ground-source heat pipe was tested in the field under conditions of negligible groundwater flow (Site 1) and conditions of fast groundwater flow (Site 2). The specific discharge (Darcy velocity) was estimated at $1.0 \mathrm{~m} / \mathrm{d}$ by the peak delay analysis of temperatures between the groundwater and subsurface water in the river.

Heat extraction rates were determined at set temperatures of $-5,0$, and $5{ }^{\circ} \mathrm{C}$. When uncertainty was considered, single heat pipes at Site 2 showed no significant improvement in the heat extraction rates when compared to Site 1, because the heat energy supplied by the soil heat conduction (Site 1) and advection (Site 2) was more than sufficient for a single heat pipe at both sites. Double heat pipes at Site 2 were $146 \%$ better than those at Site 1, on average. This increase in heat transfer rates was attributed to the groundwater flow effect. In conclusion, the heat transferred through the soil by heat conduction at Site 1 could not produce more than the heat energy extracted by the single heat pipes. In contrast, 
the heat transferred by groundwater advection could supply enough energy for double heat pipes at Site 2 .

Field experiment results at a $0{ }^{\circ} \mathrm{C}$ set temperature were discussed for applicability, considering the required road heating standard of $0.5 \mathrm{~kW}$. From this discussion, double heat pipes under groundwater flow conditions may be adequate for a snow melting system in areas near Site 2. This study, therefore, showed that groundwater flow enhances the heat extraction rates of a heat pipe, which consequently reduces the required number of heat pipes from three to two, thus reducing the construction costs of the ground-source heat pipe system.

Author Contributions: Conceptualization, Y.S.; methodology, Y.S.; software, Y.S.; validation, Y.S. and J.C.; formal analysis, J.C. and M.M.; investigation, J.C.; resources, K.N.; data curation, Y.S.; writing - original draft preparation, Y.S. and J.C.; writing—-review and editing, Y.S.; visualization, Y.S. and J.C.; supervision, K.N.; project administration, Y.S.; funding acquisition, Y.S. and K.N. All authors have read and agreed to the published version of the manuscript.

Funding: This research received no external funding.

Institutional Review Board Statement: Not applicable.

Informed Consent Statement: Not applicable.

Data Availability Statement: The data presented in this study are available on request from the corresponding author. The data are not publicly available due to privacy reasons.

Acknowledgments: Otomo Transpotation, Co., Ltd., Japan, kindly permitted us to conduct experiments at Site 2. Ariga Planning, Co., Ltd., Japan, supplied testing heat pipes for the field experiments and provided valuable suggestions in this research.

Conflicts of Interest: The authors declare no conflict of interest.

\section{References}

1. Banks, D. An Introduction to Thermogelogy: Ground Source Heating and Cooling, 2nd ed.; Wiley-Blackwell Publishing: West Sussex, UK, 2012; pp. 11-28.

2. Faghri, A. Review and Advances in Heat Pipe Science and Technology. J. Heat Transf. 2012, 134, 123001. [CrossRef]

3. Zohuri, B. Heat Pipe Design and Technology: Modern Applications for Practical Thermal Management; Springer International Publishing: Cham, Switzerland, 2016; pp. 1-41.

4. Vasiliev, L.L. Heat pipes in modern heat exchangers. Appl. Therm. Eng. 2005, 25, 1-19. [CrossRef]

5. Chang, Y.; Cheng, C.; Wang, J.; Chen, S. Heat pipe for cooling of electronic equipment. Energy Convers. Manag. 2008, 49, 3398-3404. [CrossRef]

6. Wang, X.; Zhu, Y.; Zhu, M.; Zhu, Y.; Hongtu, F.; Wang, Y. Thermal analysis and optimization of an ice and snow melting system using geothermy by super-long flexible heat pipes. Appl. Therm. Eng. 2017, 112, 1353-1363. [CrossRef]

7. Zhang, L.; Shi, Z.; Yuan, T. Study on the Coupled Heat Transfer Model Based on Groundwater Advection and Axial Heat Conduction for the Double U-Tube Vertical Borehole Heat Exchanger. Sustainability 2020, 12, 7345. [CrossRef]

8. Diao, N.; Li, Q.; Fang, Z. Heat transfer in ground heat exchangers with groundwater advection. Int. J. Therm. Sci. 2004, 43, 1203-1211. [CrossRef]

9. Molina-Giraldo, N.; Blum, P.; Zhu, K.; Bayer, P.; Fang, Z. A moving finite line source model to simulate borehole heat exchangers with groundwater advection. Int. J. Therm. Sci. 2011, 50, 2506-2513. [CrossRef]

10. Wang, H.; Yang, B.; Xie, J.; Qi, C. Thermal performance of borehole heat exchangers in different aquifers: A case study from Shouguang. Int. J. Low-Carbon Technol. 2012, 8, 253-259. [CrossRef]

11. Healy, R.W. Estimating Groundwater Recharge; Cambridge University Press: Cambridge, UK, 2018.

12. FloodMap.net. Elevation Map for Sapporo-shi, Japan. 2020. Available online: https://www.floodmap.net/Elevation/ ElevationMap/?gi=2128295 (accessed on 29 April 2021).

13. Sakata, Y.; Ikeda, M. Depth dependence and exponential models of permeability in alluvial fan gravel deposits. Hydrogeol. J. 2013, 528, 773-786. [CrossRef]

14. Hu, S.G.; Miyajima, S.; Nagaoka, D.; Koizumi, K.; Mukai, K. Study on the relation between groundwater and surface water in Toyohira-gawa alluvial fan, Hokkaido, Japan. In Groundwater Response to Changing Climate; Taniguchi, M., Holman, I.P., Eds.; CRC Press: London, UK, 2010; pp. 141-157.

15. Sakata, Y.; Katsura, T.; Nagano, K.; Ishizuka, M. Field Analysis of Stepwise Effective Thermal Conductivity along a Borehole Heat Exchanger under Artificial Conditions of Groundwater Flow. Hydrology 2017, 4, 21. [CrossRef] 
16. Sakata, Y.; Baran, G.; Suzuki, T.; Chikita, K.A. Estimate of river seepage by conditioning downward groundwater flow in the Toyohira River alluvial fan, Japan. Hydrol. Sci. J. 2016, 16, 1280-1290. [CrossRef]

17. Constantz, J. Heat as a tracer to determine streambed water exchanges. Water Resour. Res. 2008, 44. [CrossRef]

18. Water Information System. Available online: http://www1.river.go.jp/ (accessed on 3 December 2020).

19. Sakata, Y. Heat as a tracer for examining depth-decaying permeability in gravel deposits. Groundwater 2014, 53, 21-31. [CrossRef] [PubMed]

20. Niibori, Y.; Iwata, Y.; Mori, F.; Fukaya, G. A study on relation between groundwater flow and the design of ground-coupled HP system with borehole. J. Geotherm. Res. Soc. Jpn. 2002, 24, 339-348.

21. Cao, S.; Rhinehart, R. An efficient method for on-line identification of steady state. J. Process. Control 1995, 5, 363-374. [CrossRef]

22. Jouhara, H.; Robinson, A.J. Experimental investigation of small diameter two-Phase closed thermosyphons charged with water, FC-84, FC-77, and FC-3283. Appl. Therm. Eng. 2010, 30, 201-211. [CrossRef]

23. Incropera, F.P.; Dewitt, D.P.; Bergman, T.L.; Lavine, A.S. Fundamentals of Heat and Mass Transfer, 6th ed.; John Wiley \& Sons Inc.: Hoboken, NJ, USA, 2002; pp. 584-585.

24. Rohsenow, W.M.; Hartnett, J.P.; Cho, Y.I. Handbook of Heat Transfer, 3rd ed.; McGraw-Hill: New York, NY, USA, 1998; pp. 363-364.

25. Guichet, V.; Almahmoud, S.; Jouhara, H. Nucleate pool boiling heat transfer in wickless heat pipes (two-phase closed thermosyphons): A critical review of correlations. Therm. Sci. Eng. Prog. 2019, 13, 100384. [CrossRef]

26. Guichet, V.; Jouhara, H. Condensation, evaporation and boiling of falling films in wickless heat pipes (two-phase closed thermosyphons): A critical review of correlations. Int. J. Thermofluids 2020, 1, 100001. [CrossRef]

27. Nguyen-Chi, H.; Groll, M. Entrainment or flooding limit in a closed two phase thermosyphon. J. Heat Recov Syst. 1981, 1, 275-286. [CrossRef]

28. Imura, H.; Sasaguchi, K.; Kozai, H. Critical heat flux in closed two phase thermosyphon. Int. J. Heat Mass Transf. 1983, 26, 1181-1188. [CrossRef]

29. Ministry of Land, Infrastructure, Transport and Tourism. Hokkaido Regional Development Bureau Road Design Guidelines 4: Road Heating Equipment; Ministry of Land, Infrastructure, Transport and Tourism: Sapporo, Japan, 2019. (In Japanese) 